\title{
Effect of Drugs on Heme Synthesis in the Liver
}

\author{
By T. R. Tephly, E. Hasegawa and J, Baron
}

Several substances have been shown to affect hepatic heme synthesis in the rat liver. Phenobarbital and the polycyclic hydrocarbon, 3,4-benzpyrene, produce an induction of aminolevulinic acid synthetase (ALAS), the enzyme mediating the first step in heme synthesis. This is followed sequentially by increased incorporation of glycine into microsomal heme, increased microsomal protoheme, cytochrome $\mathbf{P}-\mathbf{4 5 0}$, and increases in activity of certain microsomal mixed function oxidate reactions. Microsomal cytochrome $b_{5}$ is not altered during such events. 3-amino-1,2,4-triazole inhibits increases in hepatic heme synthesis and drug oxidations produced by phenobarbital and 3,4-benzyprene, but has no effect on ALAS changes or cytochrome $b_{\overline{5}}$. Ferrochelatase, an enzyme mediating the last step in heme synthesis, is also increased by phenobarbital treatment. This enzyme was shown to be inhibited by lead and prior administration to the animal of 3,5-diethoxycarbonyl-2,4,6-trimethylpyridine (DDC). DDC also induces ALAS activity. The combined increase in ALAS activity and inhibition of ferrochelatase by DDC could account for the profound porphyria produced by this agent. (Metabolism 20: No. 2, February, 200-214, 1971)

\section{CHRONIC TREATMENT OF ANIMALS WITH CERTAIN DRUGS, such as phenobarbital and carcinogens, such as 3,4-benzpyrene, results} in the enhancement of a variety of hepatic microsomal oxidations. ${ }^{1}$ Stimulation of these oxidations appears to depend, in part, on increases in microsomal cytochrome P-450., Recently, evidence has been presented which demonstrates that many agents, including phenobarbital and 3,4-benzpyrene, are capable of inducing hepatic $\delta$-aminolevulinic acid (ALA) synthetase, ${ }^{4-7}$ the proposed initial and rate-limiting enzyme in the hepatic heme biosynthetic pathway, ${ }^{89}$ which could lead to an increased rate of synthesis of hepatic heme and which, in turn, might result in the increase of cytochrome P-450 and, in certain cases, the stimulation of certain hepatic microsomal drug oxidations. Previously, we have demonstrated that enhanced heme synthesis is essential for the induction of cytochrome $\mathrm{P}-450$ and the stimulation of certain hepatic microsomal drug oxidations. ${ }^{\mathrm{T}} 10$

The present studies demonstrate the relationship between the stimulatory effects of phenobarbital and 3,4-benzpyrene on hepatic heme synthesis, cytochrome P-450, and ethylmorphine N-demethylation. Also, the effects of pheno-

From the Department of Pharmacology, University of Michigan, Ann Arbor, Mich.

Supported by grants from the National Institute of General Medical Sciences (1P-11-GM15559), the USPHS (AM-12168), and the American Cancer Society (Institutional Research Grant $I N-40 J)$.

T. R. Tephly, M.D., Ph.D.: Associate Professor of Pharmacology, University of Michigan Medical School, Ann Arbor, Mich. E. Hasegawa, M.D.: Associate Professor, Department of Pharmacology, Kyoto Prefectural University of Medicine, Kyoto, Japan. J. Baron, Ph.D.: Postdoctoral Fellow, Department of Biochemistry, Southwestern Medical School Dallas, University of Texas, Dallas, Tex. 


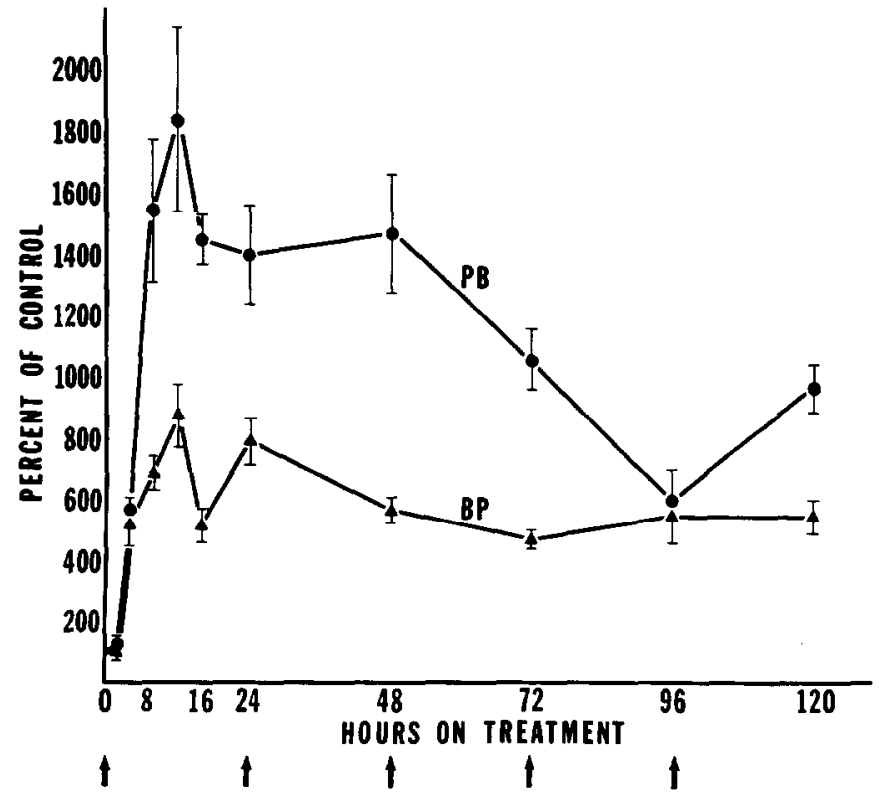

Fig. 1.-Effects of phenobarbital and 3,4-benzpyrene treatments on the activity of hepatic ALA synthetase. Rats received intraperitoneal injections of either phenobarbital (PB) (40 mg./ Kg.) or 3,4-benzpyrene (BP) $(20 \mathrm{mg} . / \mathrm{Kg}$.) at the times indicated by the arrows. Control animals received an equal volume of $0.9 \% \mathrm{NaCl}$ or corn oil. Animals were sacrificed at the time indicated, and the activity of ALA synthetase was determined in hepatic homogenates as described by Baron and Tephly. ${ }^{24}$ Each point represents the mean of at least three experiments, and the brackets represent the standard error of the mean. The average control value was $16.0 \mathrm{~m} \mu$ moles of ALA formed/Gm. liver/hr. All points were significantly $(\mathbf{P}<0.05)$ increased over control values, except the value obtained 2 hours after the initial administration of 3,4-benzpyrene.

barbital administration on hepatic mitochondrial ferrochelatase, the catalyst for the last step in heme synthesis, is revealed.

\section{Results AND Discussion}

\section{Effects of Phenobarbital and 3,4-Benzpyrene Treatments on Activity of Hepatic} $\delta$-Aminolevulinic Acid Synthetase

A single injection of either phenobarbital or 3,4-benzpyrene (Fig. 1) resulted in a rapid marked increase in the activity of hepatic ALA synthetase. The magnitude of stimulation resulting from the administration of 3,4-benzpyrene was about 50 per cent of that observed after treatment with phenobarbital, and the maximal increase in ALA synthetase activity was observed about 12 hours after the initial administration of either agent. Once maximum stimulation is produced, however, the degree of enhancement of hepatic ALA synthetase activity declines to five to ten times control values 120 hours after the onset of treatment with 3,4-benzpyrene or phenobarbital, respectively. It is interesting to note that this decline was not prevented with repeated administration of either agent or by increasing the dose of either agent during the last 72 hours 


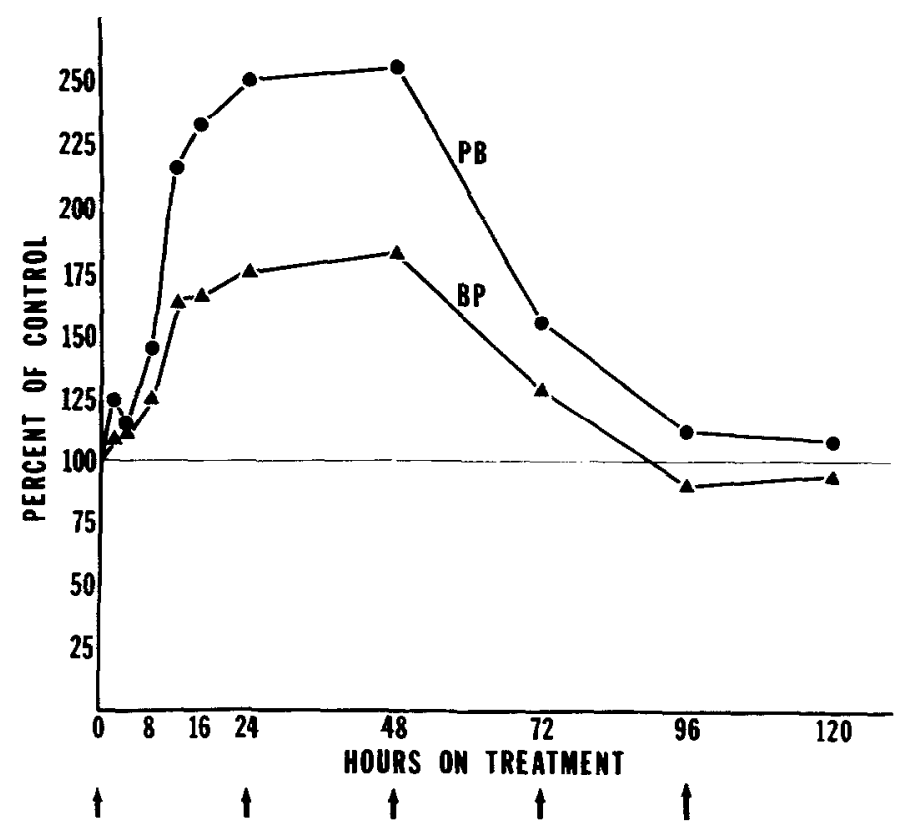

Fig. 2.-Effects of phenobarbital and 3,4-benzpyrene treatments on the capacity of the liver to synthesize microsomal heme in vivo. Phenobarbital $(40 \mathrm{mg} . / \mathrm{Kg}$.) or 3,4-benzpyrene ( $20 \mathrm{mg} . / \mathrm{Kg}$.) were administered intraperitoneally to rats every 24 hours. Control animals received an equal volume of $0.9 \% \mathrm{NaCl}$ or corn oil. At the times indicated, rats received intraperitoneally a 45 -minute pulse dose of $30 \mu \mathrm{Ci}$ of glycine- $2-{ }^{14} \mathrm{C}$, and incorporation of isotope into extracted hepatic microsomal heme was determined. The average control value was $364 \mathrm{cpm}$ in microsomal heme per mg. microsomal protein. Each value represents the mean of at least three experiments.

of study. Thus, the apparent loss of effect was not due to decreases in the effective concentrations of these agents during the late time periods of this study. Stimulation of hepatic ALA synthetase activity by phenobarbital has been reported by Wada et al. ${ }^{5}$ and by Marver. ${ }^{6}$

\section{Effects of Phenobarbital and 3,4-Benzpyrene Treatments on Hepatic Heme Synthesis In Vivo}

To study the relationship between the stimulation of hepatic ALA synthetase activity and the enhancement of hepatic heme synthesis produced by both phenobarbital and 3,4-benzpyrene, the incorporation of a 30- $\mu \mathrm{Ci}$ pulse-dose of glycine-2- ${ }^{14} \mathrm{C}$ into hepatic microsomal heme was employed as an index of hepatic heme synthesis in vivo (Fig. 2). The amount of radioactivity incorporated into microsomal heme per milligram of microsomal protein increased after the onset of treatment with either agent, with maximum stimulation occurring after approximately 48 hours. The profile then shows a return toward control values, as was seen with ALA synthetase (Fig. 1). Furthermore, in agrecment with the effects of these agents on the activity of hepatic ALA synthetase, the enhancement of hepatic heme synthesis in vivo observed after treatment with 3,4-benzpyrene was approximately 50 per cent of that observed after the administration of phenobarbital. 


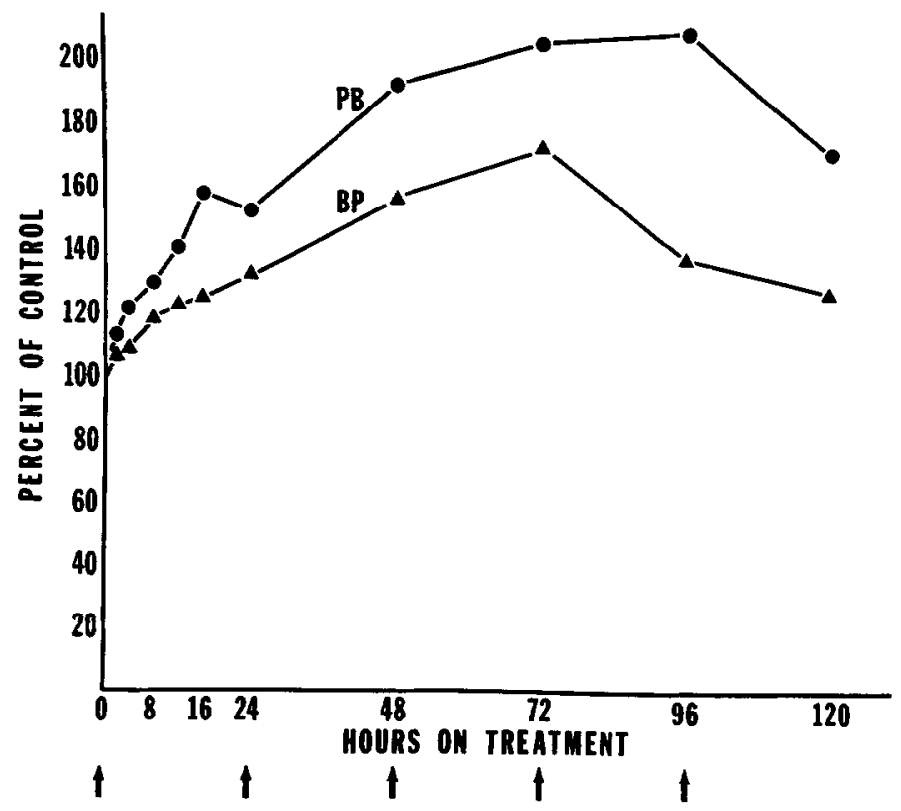

Fig. 3.-Effects of phenobarbital and 3,4-benzpyrene treatments on the hepatic microsomal content of protoheme. Conditions were the same as described for Fig. 1. Each point represents the mean of at least three experiments. The average control value was $1.06 \mathrm{~m} \mu$ moles of protoheme/mg. protein.

\section{Effects of Phenobarbital and 3,4-Benzpyrene Treatments on Hepatic Microsomal Content of Protoheme}

Treatment of rats with either phenobarbital or 3,4-benzpyrene resulted in an increase in the hepatic microsomal content of protoheme, as seen in Fig. 3. The amount of microsomal protoheme per milligram of microsomal protein and per gram of liver is significantly increased $(P<0.05) 8$ hours after phenobarbital administration and 12 hours after the administration of 3,4-benzpyrene, and these values remained elevated during the remainder of the study, increasing to a maximum 72 to 96 hours after the onset of treatment with either agent. However, these values also decline toward control values after a suitable period of time. In agreement with the effects of these agents on the activity of hepatic ALA synthetase and hepatic heme synthesis, increases in the hepatic microsomal content of protoheme produced by 3,4-benzpyrene was approximately 50 per cent of that observed after phenobarbital treatment.

\section{Effects of Phenobarbital and 3,4-Benzpyrene Treatments on Hepatic Microsomal Cytochromes}

The effects of phenobarbital and 3,4-benzpyrene treatments on the content of cytochrome P-450 in hepatic microsomes are summarized in Fig 4. Similar results have been obtained by others. ${ }^{2,11,12}$ The amount of cytochrome P-450 per milligram of microsomal protein and per gram of liver is significantly increased $(P<0.05) 8$ hours after phenobarbital administration and 12 hours after onset of 3,4-benzpyrene treatment. The level of cytochrome P-450 in 


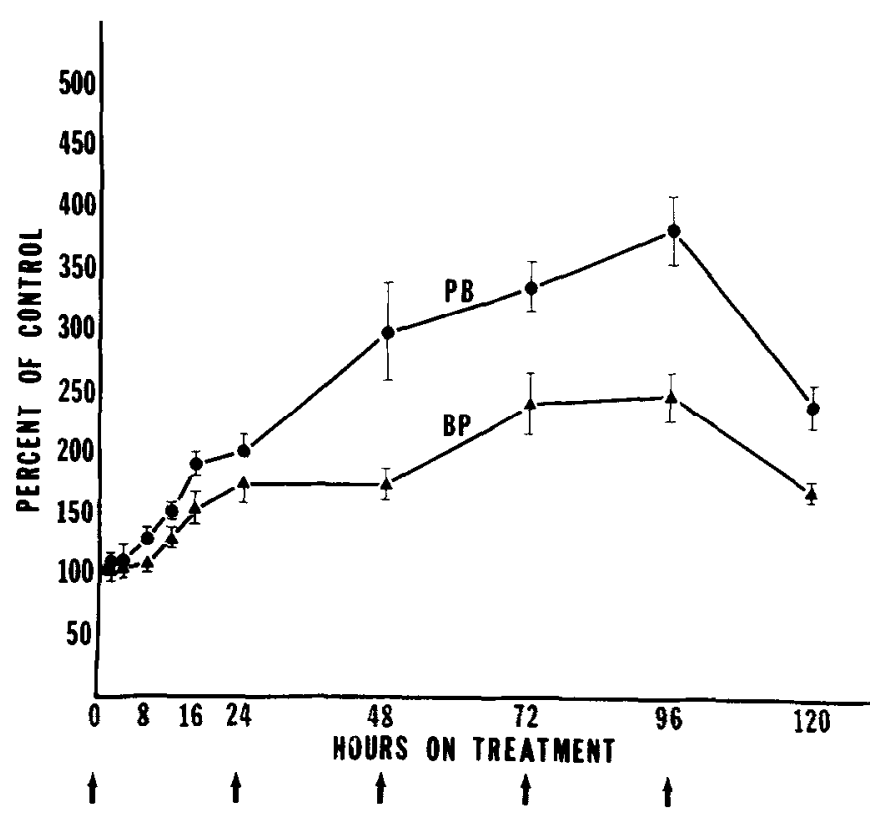

Fig. 4.-Effects of phenobarbital and 3,4-benzpyrene treatments on hepatic microsomal levels of cytochrome P-450. Conditions were the same as described for Fig. 1. Each point represents the mean of at least three experiments, and the brackets represent the standard error of the mean. The average control value was 0.05 $\Delta \mathbf{A}_{450-490 \mathrm{~m} \mu} / \mathrm{mg}$. protein.

hepatic microsomes increases until, about 96 hours after the onset of treatment with either agent, a maximum is reached. However, between 96 and 120 hours, the levels of cytochrome P-450 begin to fall toward control values, although, after 120 hours of treatment, cytochrome P-450 levels were increased approximately threefold by phenobarbital and about twofold by 3,4-benzpyrene. Increasing the doses of phenobarbital and 3,4-benzpyrene during the last 72 hours of the study did not prevent cytochrome P-450 levels from declining after maximum stimulation was achieved. The observation that the 3,4-benzpyreneinduced increase in cytochrome P-450 levels was about 50 per cent of that produced by phenobarbital agrees with the results seen with these agents on hepatic ALA synthetase activity, hepatic heme synthesis, and the hepatic microsomal protoheme content.

In spite of the stimulatory effect of phenobarbital and 3,4-benzpyrene on microsomal content of cytochrome P-450, the levels of cytochrome $b_{5}$ in hepatic microsomes were unaffected during the first 48 hours of treatment, although, as seen in Fig. 5, the amount of cytochrome $b_{5}$ per milligram of microsomal protein did increase $(P<0.05)$ between 96 and 120 hours after the onset of treatment with either agent.

These results indicate that enhanced formation of ALA is followed sequentially by an increased hepatic capacity to synthesize heme in vivo, increases in microsomal P-450 and protoheme. However, no substantial effects on cytochrome $b_{5}$ levels were produced during these events. 


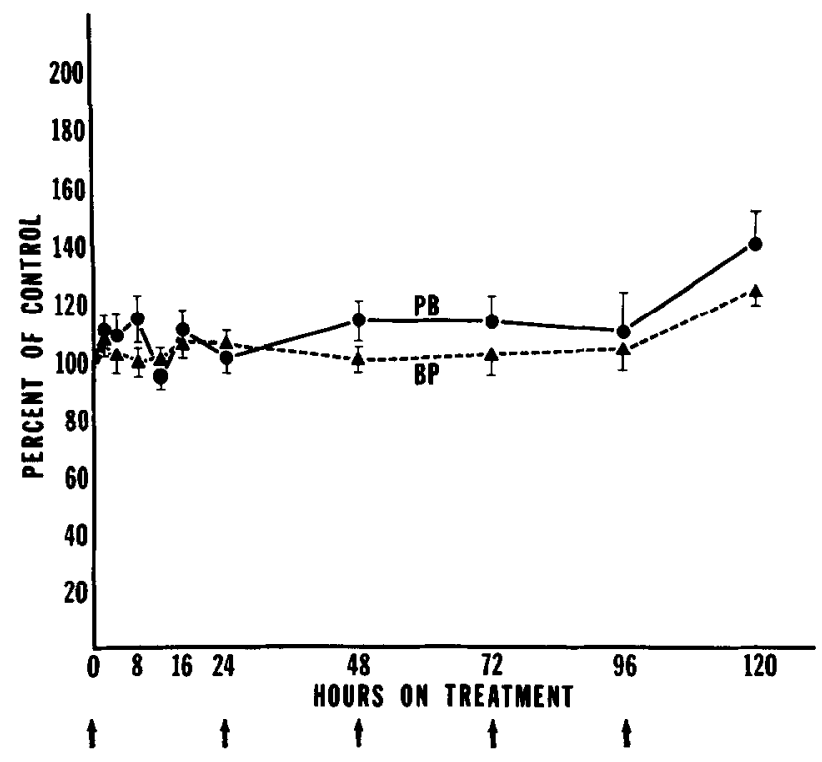

Fig. 5.-Effects of phenobarbital and 3,4-benzpyrene treatments on hepatic microsomal levels of cytochrome $b_{5}$. Conditions were the same as described for Fig. 1 . Each point represents the mean of at least three experiments, and the brackets represent the standard error of the mean. The average control value was $0.22 \mathrm{~m} \mu$ moles of cytochrome $b_{5} / \mathrm{mg}$. protein.

Effect of Aminotriazole on Hepatic Microsomal Heme Synthesis and on Stimulation of Hepatic Microsomal Heme Synthesis by Phenobarbital

If the synthesis and stimulation of synthesis of microsomal P-450 is dependent on heme synthesis, then an inhibitor of heme synthesis ought to be capable of inhibiting P-450 synthesis and the induction of P-450 synthesis produced by phenobarbital and other inducers. A well-known inhibitor of hepatic catalase activity, 3-amino-1,2,4-triazole (AT) has been used in our laboratory as an inhibitor of methanol metabolism in the rat. ${ }^{13,14}$ This substance has been shown to inhibit $\delta$-aminolevulinic acid dehydratase activity, ${ }^{15}$ the catalyst for the second step in heme synthesis, that responsible for the conversion of ALA to porphobilinogen. We showed that AT was an inhibitor of ALA dehydratase

Table 1.-Effects of Aminotriazole (AT) and Phenobarbital (PB) in the Incorporation of $\delta$-aminolevulinic-4-14 C Acid into Microsomal Heme in Vivo*

\begin{tabular}{cc}
\hline Pretreatment & Per Cent of Control \\
\hline AT & $59.4 \pm 9.1 \dagger$ \\
PB & $87.0 \pm 10.7$ \\
PB + AT & $77.2 \pm 20.0$
\end{tabular}

* Rats received intraperitoneally a 60 -minute pulse of $10 \mu \mathrm{Ci}$ of $\mathrm{ALA}-{ }^{14} \mathrm{C} 1$ hour after the intraperitoneal administration of either AT $(3 \mathrm{Gm} . / \mathrm{Kg}$.$) , PB (40 \mathrm{mg} . / \mathrm{Kg}$.) or PB and AT. Control animals received an equal volume of saline 1 hour before the pulse. Incorporation into extracted microsomal heme was determined as described previously. ${ }^{10}$ The control value was $8729 \mathrm{cpm} / \mathrm{m} \mu$ mole protoheme $/ \mathrm{ml}$. ether extract.

$\dagger$ Values represent the mean \pm S.E.M. of three experiments. 
Table 2.-Effects of Aminotriazole (AT) and Phenobarbital (PB) on the Incorporation of ${ }^{59} \mathrm{FeCl}_{3}$ into Hepatic Microsomal Heme in Vivo*

\begin{tabular}{lrc}
\hline Pretreatment & \multicolumn{2}{c}{ Per Cent of Control } \\
\hline AT & Microsomes & Extracted Microsomal Heme \\
PB & $62.7 \pm 16.7 \dagger$ & $54.8 \pm 11.9$ \\
PB \pm AT & $155.5 \pm 14.5$ & $144.7 \pm 21.5$ \\
& $79.4 \pm 19.6$ & $69.6 \pm 12.7$
\end{tabular}

* Rats received intraperitoneally a 60 -minute pulse of $50 \mu \mathrm{Ci}$ of ${ }^{59} \mathrm{FeCl}_{3} 4$ hours after the intraperitoneal administration of either AT (3 Gm./Kg.), Pb (40 mg./ Kg.) or both AT and PB. Control animals received an equal volume of saline 4 hours before the pulse. Incorporation was determined as described previously. 10 The control value for microsomes was $238.4 \mathrm{cpm} / \mathrm{m} \mu$ mole protoheme $/ \mathrm{ml}$. microsomes while that for extracted heme was 45.3 $\mathrm{cpm} / \mathrm{m} \mu$ mole protoheme $/ \mathrm{ml}$. ether extract.

$\dagger$ Values represent the mean \pm S.E.M. of three experiments.

in vitro ${ }^{10}$ but not a very potent one. However, in vivo, AT was a fairly effective inhibitor of the incorporation of $\mathrm{ALA}^{-14} \mathrm{C}$ into microsomal heme. This is seen in Table 1. AT produced at 40 per cent inhibition of the rate of incorporation of ALA into microsomal heme and phenobarbital had no effect on the incorporation of ALA into microsomal heme. These results were expected because, by studying ALA incorporation, we are probably bypassing the ratelimiting step in heme synthesis, and this is where phenobarbital is exerting its major stimulatory effect under the conditions of this experiment. Table 2 shows that AT also inhibits ${ }^{\circledR 9} \mathrm{Fe}$ incorporation into microsomes and into microsomal heme. Phenobarbital produced a stimulation of ${ }^{59} \mathrm{Fe}$ incorporation, which was reversed by simultaneous administration of AT. Therefore, AT is capable of inhibiting hepatic heme synthesis and reverses the stimulation of the heme synthesis produced by phenobarbital.

The effect of AT on the induction of hepatic microsomal P-450 by phenobarbital is shown in Fig. 6. The expected stimulatory effect of phenobarbital is shown as well as the effect of AT alone. Treatment with AT alone produced a minimum decrease in P-450 levels of nearly 50 per cent approximately 16 hours after administration, and the simultaneous administration of AT with phenobarbital effectively reduced the induction of P-450 produced by phenobarbital. We feel that this points out the dependence of P-450 synthesis and the dependence of the phenobarbital stimulation of P-450 synthesis on heme synthesis. AT had no effect on the concentration of microsomal cytochrome $b_{\bar{v}}$ in microsomes which was not unexpected since phenobarbital had no effect on $b_{5}$ synthesis (Fig. 5). The pattern of ethylmorphine N-demethylation (Fig. 7) resembles that seen with $\mathrm{P}-450$, namely, a 40 per cent decrease in ethylmorphine demethylation in hepatic microsomes with AT treatment alone, the stimulation by phenobarbital administration, and the reversal of phenobarbital induction by AT. This suggests that under certain conditions ethylmorphine metabolism is dependent upon P-450 levels. However, this is not always the case, as has been shown previously. ${ }^{10}$

Several experiments show that AT does not exert its effect through inhibition of protein synthesis. Amino acid incorporation into microsomal protein is not altered by $\mathrm{AT}^{10}$ and the stimulation of a microsomal protein, NADPH- 

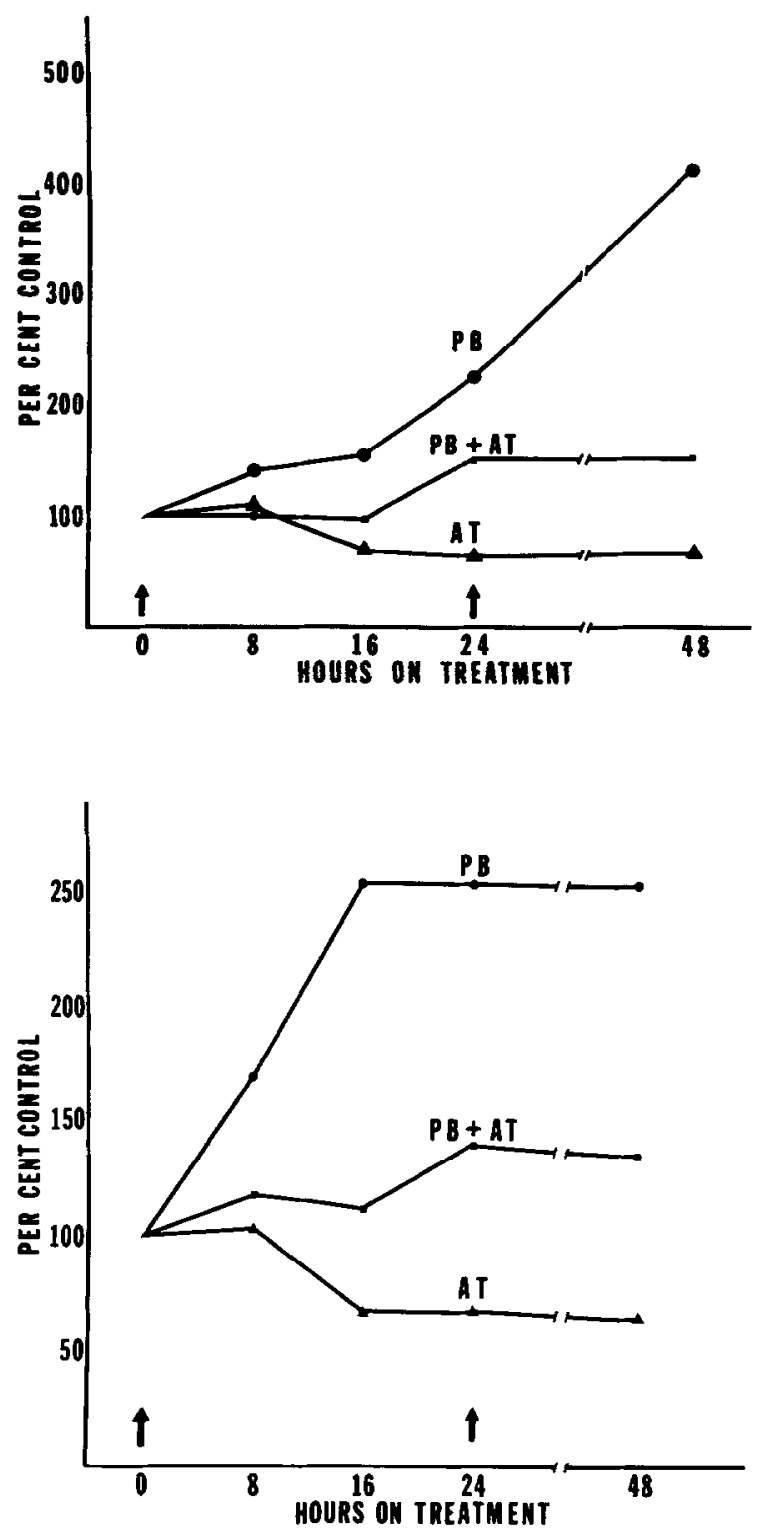

Fig. 6.-Effect of aminotriazole ( $3 \mathrm{Gm} . / \mathrm{Kg}$.) (AT) on the induction of hepatic microsomal cytochrome P-450 by phenobarbital (40 mg./ $\mathrm{Kg}$.) (PB). Drugs were administered intraperitoneally at zero time, control animals receiving an equal volume of $0.9 \% \mathrm{NaCl}$, and the animals either were killed 8,16 , or 24 hours later or received a second series of injections 24 hours after the first and then were killed 24 hours later. Cytochrome P-450 was determined as described by Baron and Tephly. ${ }^{10}$ Each point represents the mean of at least four experiments. The average control value was $0.23 \quad \Delta . \mathbf{A}_{450-490}$ unit/mg. protein.

Fig. 7.-Effect of aminotriazole $(3 \mathrm{Gm} . / \mathrm{Kg}$.) (AT) on induction of the $\mathrm{N}$-demethylation of ethylmorphine by phenobarbital (40 mg./ Kg.) (PB). Conditions were the same as described for Fig. 6. Each point represents the mean of at least four experiments. The average control value was 2.8 $\mathrm{m} \mu$ moles of formaldehyde $/ \mathrm{mg}$. protein/min.

cytochrome $\mathrm{c}$ reductase, by phenobarbital is not affected by AT under conditions that did interrupt the effect of phenobarbital on P-450 (Fig. 8). Furthermore, it has been shown by Raisfeld et al. ${ }^{16}$ that AT had no effect on the increases in microsomal phospholipid or proliferation of smooth membranes produced by phenobarbital. Also, AT has no effect on the induction of ALA synthetase produced by phenobarbital administration.

Studies on Hepatic Mitochondrial Ferrochelatase

The last step in heme synthesis, that mediated by ferrochelatase, occurs in 


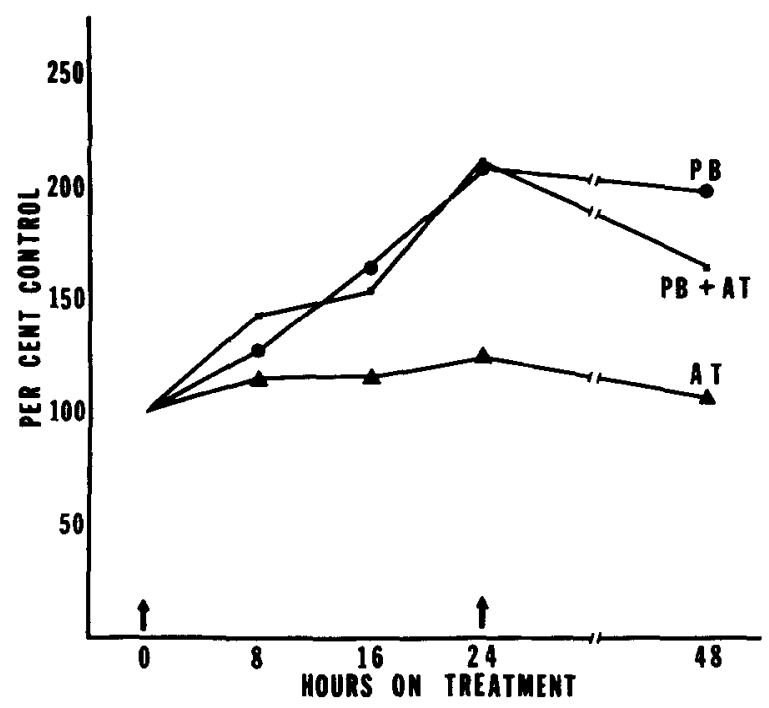

Fig. 8.-Effect of aminotriazole $(3 \mathrm{Gm} . / \mathrm{Kg}$.) (AT) on the induction of NADPHcytochrome c reductase by phenobarbital (40 mg./ Kg.) (PB). Conditions were the same as described for Fig. 6. Each point represents the mean of at least four experiments. The average control value was $39.1 \mathrm{~m} \mu$ moles of cytochrome $c$ reduced per milligram of protein per minute.

the mitochondria and is closely associated with ALA synthetase. Because of the striking effects of phenobarbital and other substances on ALA synthetase, we have recently turned our attention to an understanding of this enzyme and its properties. Our studies were first directed at development of an assay for this enzyme and, since others ${ }^{17}$ had employed cobalt as substrate instead of iron, we began our work by studying the incorporation of cobalt into protoporphyrin IX under aerobic conditions. Figure 9 shows the typical spectrum that develops

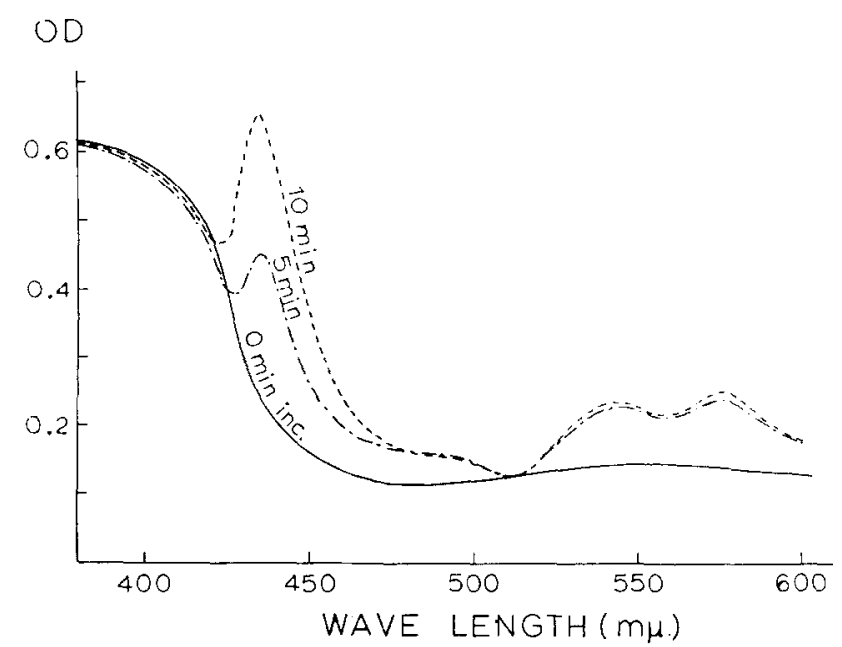

Fig. 9.-The formation of the cobalt protoporphyrin IX complex in rat liver mitochondria. Mitochondria were prepared from livers of $50 \mathrm{gram}$, male, SpragueDawley rats. Reactions were carried out aerobically at $37^{\circ} \mathrm{C}$ and they contained $50 \mu \mathrm{M}$ protoporphyrin IX, $50 \mu \mathrm{M}$ cobalt chloride, $0.1 \%$ Tween 80 , mitochondria, $3 \mathrm{mg}$. of protein $/ \mathrm{ml}$. reaction mixture and glycine buffer, $0.1 \mathrm{M}, \mathrm{pH} 7.8$. The spectra were measured on a Shimadzu split-beam spectrophotometer. Blank reactions had cobalt added just prior to recording and reactions were linear to 75 minutes under these conditions. 


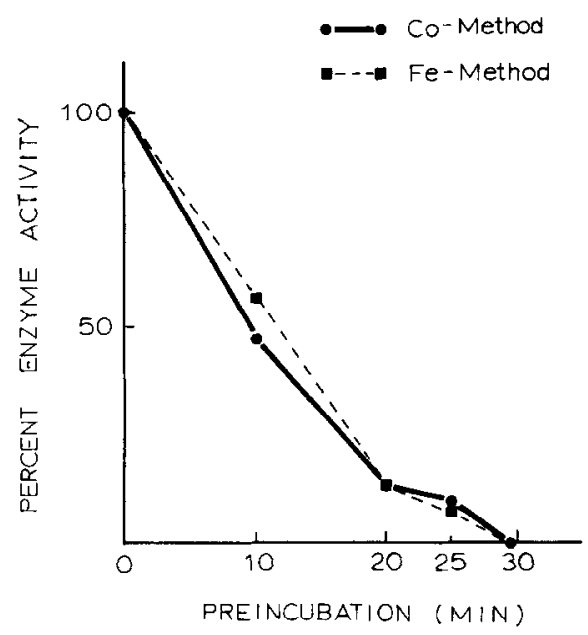

Fig. 10.-The effect of preincubation of mitochondria at $60^{\circ} \mathrm{C}$ on the activity of cobalt and ferrochelatase activity. Ferrochelatase activity was determined by the method of Porra and Jones ${ }^{18}$ except that GSH was omitted from reaction mixtures and glycine buffer was employed. Cobalt chelatase activity was determined as in Fig. 9.

when cobalt and protoporphyrin IX are reacted with hepatic mitochondria. Mitochondria were prepared according to the method of Jones and Jones, ${ }^{17}$ with one exception. We found that Tris buffer produced a spectrum when combined with cobalt and, therefore, we employed glycine buffer for our preparation. When either cobalt, protoporphyrin IX, or mitochondria were omitted from the reaction mixtures, no spectra were obtained. Furthermore, the formation of the absorbance band at about $430 \mathrm{~m} \mu$ was dependent on time and protein concentration. This was our routine assay for the incorporation of cobalt into protoporphyrin IX. In addition to this assay, we used the method of Porra and Jones ${ }^{18}$ to measure the formation of heme from ferrous ion and protoporphyrin IX under anacrobic conditions. Reduced glutathione was omitted from the reaction mixture.

The distribution of cobalt and ferrochelatase has been reported to be similar, ${ }^{18}$ and we have also conducted several experiments that pointed to a single enzyme mediating both reactions. For example, cobalt and ferrochelatase activity yield similar thermolability to heat (Fig. 10). It has been reported by Mazanowska et al. ${ }^{19}$ that ether stimulates ferrochelatase activity. It can be seen in Fig. 11 that ether stimulates both cobalt and ferrochelatase activity, but not to the same degree. This was the first indication to us that there might be a difference between these activities.

Table 3 shows that when copper or nickel chloride was employed in reaction mixtures, no effect was obtained on the cobalt chelatase activity, but a profound inhibition of ferrochelatase activity was observed. Ferric ion has no effect on either system and EDTA inhibits both systems to about the same extent. Mercury and silver salts were not effective inhibitors of either system and parahydroxymercuribenzoate was almost completely ineffective as an inhibitor. Lead was shown to be a potent inhibitor of ferrochelatase activity, which was expected since profound coproporphyrinuria is found in lead poisoning. It has not been possible to examine the effect of lead on cobalt chelatase activity at this time. However, these data suggest that cobalt and ferrochelatase may be different enzymes. 
年

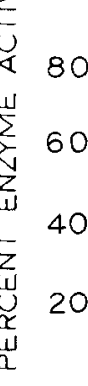
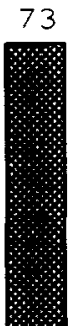

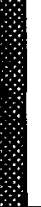
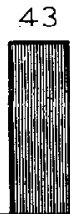

Co-Method

Fe-Method

Fig. 11.-The effect of diethylether on cobalt and ferrochelatase activity in rat liver mitochondria. Cobalt chelatase was assessed as described in Fig. 9 and ferrochelatase activity was measured as described in Fig. 10. Diethylether (peroxide-free). $50 \mu \mathrm{l}$.. was added to reaction mixtures and activity obtained was compared to that found in the absence of ether (100\% activity).

Figure 12 shows a distribution of cobalt and ferrochelatase activity in various organs of the rat with activity in the liver represented as 100 per cent. These data clcarly show that the activity of cobalt chelatase in the heart is very low when compared to the liver, but that ferrochelatase activity is even higher in the heart than in the liver. The dissimilarities in the ratios of ferrochelatase and cobalt chelatase activities in the various rat organs indicated further that different enzymes are involved.

After these observations were made we studied the effect of phenobarbital administration on ferrochelatase activity (Fig. 13). Many months before we had observed that phenobarbital administration had no effect on the cobalt chelatase activity in the rat liver. However, when ferrochelatase activity was studied using the pyridine hemochrome formation as a measure of the activity of this enzyme, a substantial increase in mitochondrial activity was observed. Recently, we have shown that this effect can be prevented with simultaneous administration of cycloheximide. Therefore, we view this as a true induction.

Table 3.-Effect of Various Metals on Cobalt and Ferrochelatase Activity in Rat Liver Mitochondria*

\begin{tabular}{lrrr}
\hline & \multirow{2}{*}{ Concentration $(\mathbf{M})$} & \multicolumn{2}{c}{ Per Cent Inhibition } \\
\cline { 3 - 4 } & & Ferrochelatase & Cobalt Chelatase \\
\hline $\mathrm{Fe}^{3+}$ & $10^{-4}$ & 0 & 10 \\
$\mathrm{Cu}^{2}+$ & $10^{-4}$ & 52 & 6 \\
$\mathrm{Ni}^{2+}$ & $10^{-4}$ & 67 & 0 \\
$\mathrm{Hg}^{2}+$ & $10^{-4}$ & 17 & 15 \\
$\mathrm{Ag}^{+}$ & $10^{-1}$ & 38 & 20 \\
$\mathrm{~Pb}^{2+}$ & $10^{-3}$ & 89 & \\
& $10^{-4}$ & 76 & \\
& $10^{-5}$ & 35 & \\
& $10^{-6}$ & 13 & 100 \\
& $10^{-7}$ & 0 & 83
\end{tabular}

* Assays were employed as described in Figs. 9 and 10. Metals were used as their chloride salts except for silver sulfate. The anions had no effect on activity. 


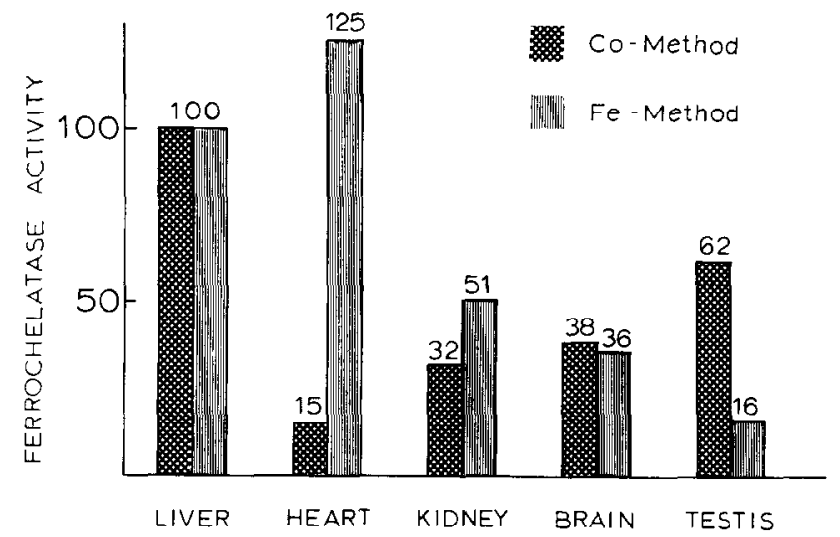

Fig. 12.-Distribution of cobalt and ferrochelatase activity in mitochondria obtained from various organs of the rat. Mitochondria were assayed for cobalt and ferrochelatase activity and compared to that found in hepatic mitochondria of untreated rats. Activity in hepatic mitochondria was considered as $100 \%$.

Addition of phenobarbital to reaction mixtures has no effect on the enzyme.

DDC (3,5-diethoxycarbonyl-2,4,6-trimethylpyridine) is a well-known porphyria-producing agent which is a potent inducer of ALA synthetase. ${ }^{8}$ It was found that after injection of rats with this agent $(300 \mathrm{mg}$. $/ \mathrm{Kg}$.) there was no effect on cobalt chelatase activity, but a substantial inhibition of ferrochelatase activity was produced. This is shown in Fig. 14 with the effect of phenobarbital obtained 24 hours after the start of treatment. Onisawa and Labbe ${ }^{20}$ had reported this effect previously, but we feel that this observation is an essential one in explaining the porphyria produced by DDC. Not only must one have an induction of ALA synthetase, but the development of a rate-limiting step further on in the heme synthetic pathway for the production of a porphyria as well.

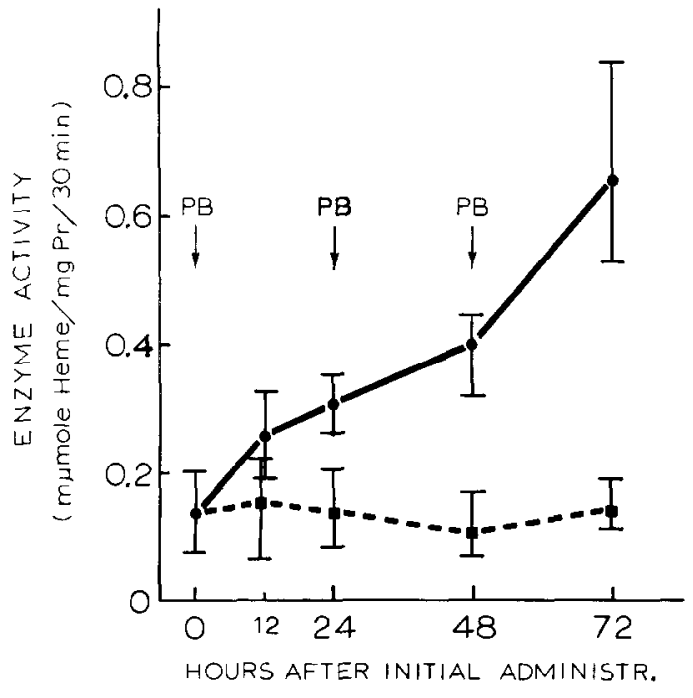

Fig. 13.-The effect of phenobarbital administration on rat liver mitochondrial ferrochelatase activity. Male, SpragueDawley rats $(50 \mathrm{Gm}$.) were administered phenobarbital sodium (60 mg./ Kg.) at the arrows (solid line) or saline (dashed line). Activity was determined by the pyridinc hemochrome assay (Fig. 10). Each point represents the mean value \pm S.E.M. from 4 animals. No effect of phenobarbital on cobalt chelatase activity was observed. All animals were fasted for 24 hours prior to sacrifice but water was allowed ad libitum. 
Fig. 14.-Comparison of the effects of phenobarbital (PB) and DDC treatments on the activity of rat hepatic mitochondrial ferrochelatase. Male, Sprague-Dawley rats $(150 \mathrm{Gm}$.) were treated with either phenobarbital sodium $(60 \mathrm{mg} . / \mathrm{Kg}$ ) or DDC (3,5-diethoxycarbonyl-2,4,6-trimethylpyridine) $\quad(300$ mg./Kg.) 24 hours prior to sacrifice. Neither agent had an effect when added directly to reaction mixtures. Both agents were injected intrapcritoneally in saline (phenobarbital) or dimethylsulfoxide (DDC). Dimethylsulfoxide had no effect when compared to saline controls. The degree of inhibition produced by DDC treatment is dependent upon the time periods during which measurements are taken. These data represent the difference in rate of formation of heme during a period of linear product formation. However, no activity was obtained in mitochondria prepared from DDC-treated rats during the first 10 minutes of incubation.

These studies document the induction of rat hepatic mitochondrial ferrochelatase by the chronic treatment of rats with phenobarbital, which was observed only when pyridine hemochrome formation was measured and not when the formation of the cobalt protoporphyrin IX complex was examined. Also, there is an insensitivity of cobalt chelatase activity to copper and nickel, metals that inhibited pyridine hemochrome formation. One likely explanation for this dissociation is that a different enzyme mediates cobalt complexation. However, one cannot exclude the possibility that a metal carrier system for iron is being affected with phenobarbital treatment and with certain metals. but that no carrier or a different carrier is required for cobalt transport to the enzyme,

It is interesting to note that the temporal response of ferrochelatase activity after phenobarbital administration is quite different from that observed with ALA synthetase activity. One may suggest that the ALA synthetase activity and ferrochelatase are reciprocally related and that increases in ferrochelatase activity are promoted through increased flux of porphyrin substrate brought about by increased ALA synthetase activity. In turn, the increased heme formed by these events may be responsible for the decreases in ALA synthetase activity upon prolonged phenobarbital administration. It has been suggested by Granick and his colleagues, ${ }^{9,21,22}$ that heme participates in the regulation of the synthesis of ALA synthetase on the basis of a feed-back repression. Scholnick et al. ${ }^{23}$ have described the direct inhibition of soluble ALA synthetase by heme, which could account for another manner of control of heme synthesis in the mammal. It is also possible that the synthesis of ALA synthetase and ferrochelatase are independent of each other. 


\section{REFERENCES}

1. Conney, A. H.: Pharmacological implications of microsomal enzyme induction. Pharmacol. Rev. 19:317, 1967.

2. Remmer, H., and Merker, H. J.: Effect of drugs on the formation of smooth endoplasmic reticulum and drug metabolizing enzymes. Ann. N.Y. Acad. Sci. 123:79, 1965.

3. Sladek, N. E., and Mannering, G. J.: Induction of drug metabolism. I. Differences in the mechanisms by which polycyclic hydrocarbons and phenobarbital produce their inductive effects on microsomal $N$-demethylating systems. Molec. Pharmacol. 5:174, 1969.

4. Marver, H., Schmid, R., and Schutzel, H.: Heme and methemoglobin: Naturally occurring repressors of microsomal cytochrome. Biochem. Biophys. Res. Commun. 33:696, 1968.

5. Wada, O., Yano, Y., Urata, G., and Nakao, K.: Behavior of hepatic microsomal cytochromes after treatment of mice with drugs known to disturb porphyrin metabolism in liver. Biochem. Pharmacol. 17:595, 1968.

6. Marver, H. S.: The role of heme in the synthesis and repression of microsomal protein. In: Gillette, J. R., Conney, A. H., Cosmides, G. J., Estabrook, R. W., Fouts, J. R., and Mannering, G. J. (Eds.): Microsomes and Drug Oxidations. New York, Academic, 1969.

7. Baron, J., and Tephly, T. R.: The role of heme synthesis during the induction of hepatic microsomal cytochrome P-450 and drug metabolism produced by benzpyrene. Biochem. Biophys. Res. Commun. 36:526, 1969.

8. Granick, S., and Urata, G.: Increase in activity of $\delta$-aminolevulinic acid synthetase in liver mitochondria induced by feeding of 3,5-dicarbethoxy-1,4-dihydrocollidine. J. Biol. Chem. 238:821, 1963.

9. Granick, S.: The induction in vitro of the synthesis of $\delta$-aminolevulinic acid synthetase in chemical porphyria: A response to certain drugs, sex hormones, and foreign chemicals. J. Biol. Chem, 241:1359, 1966.

10. Baron, J., and Tephly, T. R.: Effect of 3-amino-1,2,4-triazole on the induction of rat hepatic microsomal oxidases, cytochrome P-450, and NADPH-cytochrome c reductase by phenobarbital. Molec. Pharmacol. 5:10, 1969.

11. Greim, H., Schenkman, J. B., Klotz- bücher, M., and Remmer, H.: The influence of phenobarbital in the turnover of hepatic microsomal cytochrome $b_{5}$ and cytochrome P-450 heme in the rat. Biochim. Biophys. Acta 201:20, 1970.

12. Orrenius, S.: Further studies on the induction of the drug-hydroxylating enzyme system of liver microsomes. J. Cell Biol. 26: $725,1965$.

13. Tephly, T. R., Mannering, G. J., and Parks, R. E., Jr.: Studies on the mechanism of inhibition of liver and erythrocytic catalase activity by 3 -amino-1,2,4-triazole (AT). I. Pharmacol. Exp. Ther. 134:77, 1961.

14. Tephly, T. R., Parks, R. E., Jr., and Mannering, G. J.: Methanol metabolism in the rat. J. Pharmacol. Exp. Ther. 143:292, 1964.

15. Tschudy, D. P., and Collins, A.: Effect of 3-amino-1,2,4-triazole on $\delta$-aminolevulinic acid dehydrase activity. Science 126:168, 1957.

16. Raisfeld, I. H., Bacchin, P., Hutterer, F., and Schaffner, F.: The effect of 3-amino1,2,4-triazole on the phenobarbital-induced formation of hepatic microsomal membranes. Molec. Pharmacol. 6:231, 1970.

17. Jones, M. S., and Jones, O. T. G.: Evidence for the location of ferrochelatasc on the inner membrane of rat liver mitochondria. Biochem. Biophys. Res. Commun. $31: 977,1968$.

18. Porra, R. J., and Jones, O. T. G.: Studies on ferrochelatase: I. Assay and properties of ferrochelatase from a pig-liver mitochondrial extract. Biochem. J. 87:181, 1963.

19. Mazanowska, A. M., Neuberger, A., and Tait, G. H.: Effect of lipids and organic solvents on the enzymic formation of zinc protoporphyrin and heme. Biochem. J. 98: $117,1966$.

20. Onisawa, J., and Labbe, R.: Effects of diethyl-1,4-dihydro-2,4,6-trimethylpyridine-3,5-dicarboxylate on the metabolism of porphyrins and iron. J. Biol. Chem. 238:724, 1963.

21. Granick, S.: Hepatic porphyria and drug-induced or chemical porphyria. Ann. N.Y. Acad. Sci. 123:188, 1965.

22. Kappas, A., and Granick, S.: Steroid induction of porphyrin synthesis in liver cell 
culture. II. The effects of heme, uridine diphosphate glucuronic acid, and inhibitors of nucleic acid and protein synthesis on the induction process. J. Biol. Chem. 243:346, 1968.

23. Scholnick, P. L., Hammaker, L., and Marver, H. S.: Soluble hepatic $\delta$-aminolevulinic acid synthetase: End-product inhibition of the partially purified enzyme. Proc. Nat. Acad. Sci. U.S.A. 63:65, 1969.

24. Baron, J., and Tephly. T. R.: Further studies on the relationship of the stimulatory effects of phenobarbital and 3.4-benzpyrene on hepatic heme synthesis to their effects on hepatic microsomal drug oxidations. Arch. Biochem. (in press). 